By DOROTHY E. COLE

\title{
Some Characteristics of Reference Work ${ }^{1}$
}

$\mathrm{T}$ HERE ARE several generalizations which emerge from an examination of the literature on the measurement of reference work. Evaluation per se does not enter into the earlier literature, which is concerned in the main with a description of the techniques, tools, and intellectual rewards of reference librarianship. The earliest mention of reference records was made by Marilla W. Freeman in $1913 .{ }^{2}$ Since that date a number of librarians have attempted to cope with the problem of reference measurement and have approached the problem in several different ways. A number of plans for classifying reference questions have been developed both in theory and in actual library practice. These classifications have been based on: (I) the subject matter of the questions, (2) the amount of skill or knowledge necessary to answer them, or a combination of the two. The element of time has frequently been used to distinguish between simple and complex questions; frequently the latter are classified as complex because the process of answering them consumes more time. Examples of these classifications may be found in the articles by Swift, ${ }^{3}$ Alexander, ${ }^{4}$ Hazeltine, ${ }^{5}$ and Barlow. ${ }^{6}$

1 Condensed from an M.A. thesis, "An Analysis of Adult Reference Work in Libraries," submitted to the Graduate Library School, University of Chicago, in I943.

2 Freeman, Marilla Waite. "Scientific Management, and the Reference Department as a Bureau of Information." A.L.A. Bulletin 7: 331-36, July 1913.

S Swift, Iva I. "Classifying Readers' Questions." Wilson Bulletin 8: 274-75, January 1934.

4Alexander, Carter. "The Technique of Library Searching." Special Libraries 27: 230-38, September ${ }^{9} 6$.
Hazeltine, Mary Emogene. "Fundamentals of Ref"Hazeltine, Mary Emogene. "Fundamentals of Ref-
erence Service." Wisconsin Library Bulletin I5: 85-90, April 1919.
Many of the analyses of actual reference questions have been made in the public library field. Attention should be directed to the studies of Kingman, ${ }^{7}$ Conner, ${ }^{8}$ Guerrier, ${ }^{9,10}$ and Darsie. ${ }^{11}$ In some studies the questions were classified by subject, while in others an attempt was made to classify them according to their content or complexity. When questions are classified by subject, the field of the social sciences is usually found to be the subject group in which most questions fall, while studies based on the nature of the questions show that the informational or fact-finding group is the largest. The time spent in answering reference questions seems to suggest a basis for estimating the cost of reference work and the skill of the reference worker.

\section{The Nature and Scope of Investigation}

No precise and exact formula for evaluating reference work has yet been devised; furthermore, the nature of the reference process seems to preclude the possibility of such an accomplishment. Certainly it was not the intention of the writer to aim at such a goal. On' the other hand, previous studies of reference work based on certain

Barlow, S. H. "Suggestion for Estimating Use of 0 the Reference Library." Library World 4I: 29-30, August-September 1938 .

7 Kingman, Marion C. "Reference Work in an Branch Library." A.L.A. Bulletin 32: 834-35, Oct. 15. 1938 .

8 Conner, Martha. "What a Reference Librarian Should Know." Library Journal 52: 415-18, Apr. 15, 1927.

Guerrier, Edith. "Measurement of Reference Service in a Branch Library." A.L.A. Bulletin 29: 632-37, September 1935 .

"The Measurement of Reference Service." Library Journal 61: 529-31, July 1936.

11 Darsie, Helen H. "Measuring the Results of Reference Service." A.L.A. Bulletin 29: 604.05, Sep. tember 1935 . 
quantitative or measurable aspects have increased our understanding of the nature of reference practice in libraries. The aim of the present investigation, then, is to augment this fund of knowledge.

Previous investigations of reference work have given scant attention to certain segments of the process. Analyses of reference questions, as heretofore mentioned, have been made largely in the public library field, yet a great deal of important reference service is being rendered in academic and special libraries. What are the elements of similiarity and difference in these three types of reference service?

At the present time we have but slight knowledge of the relation between the reader's occupation and his reference requests. While in the academic and special libraries the occupational distribution of the readers may be determined by the nature of the institution, the public library, in theory at least, should be meeting the needs of readers of all occupations. The present study includes an analysis of the occupational background of users of the reference department.

It has been observed that many library readers have difficulty in expressing their reference needs. Another area of investigation, then, is the difference between what reference patrons want and what they ask for. One of the tasks required of reference

- librarians is that of translating vague requests into meaningful terms. Generalizations regarding typical behavior patterns of patrons should be helpful for actual reference practice. An analysis of unanswered reference questions will also be undertaken.

The final aspect of reference work covered in this paper is that of the sources of reference information. What books and other materials were found useful in answering reference questions? Into what patterns do they fall? The findings should be of interest to those responsible for book selection in libraries and to those who teach basic courses in reference work.

\section{Gathering the Data}

The questions on which this study is based were recorded in thirteen libraries during the month of April 194I. Not all of the questions received by these libraries during the period were reported, since librarians found it impossible to record them because of pressure of business. Eleven of the libraries are in the Chicago area, one in central Illinois, and one in the western section of the United States. In addition a number of questions received at the St. Louis Public Library on one day in January I94I were used. ${ }^{12}$ The following types of libraries were represented: large, medium, and small public libraries, junior and liberal arts colleges, university departmental libraries, and special libraries in the fields of social science, business and technology, and general reference. The form for recording the questions provided space for the following items:

I. What patron asked for

2. Exact. statement of the question

3. Occupation of the patron

4. Specific books and other tools used in finding the answer

5. Other functions performed

6. Was question answered satisfactorily? If not, indicate reason.

All of the libraries were furnished copies of instructions for filling out the forms, in order to insure uniform and comparable results.

\section{Limitations of the Study}

First, the study does not attempt to establish a technique for measuring the reference work of an individual library, although a library might gain a clearer understanding of its reference work by

12 Information Please: $A$ Typical Day in the Refer. ence Departments of the St. Lowis Public Library.... St. Louis, Public Library, I94I. 
keeping similar records. Second, the study does not consider the element of time in classifying reference questions. Finally, it does not include questions from large research libraries which are used primarily by scholars.

The 1026 reference questions upon which this study is based were classified by subject, since this method offered a convenient means of comparison with earlier studies. It is obvious from the subject distribution that no field of knowledge, at least at the level represented by the second summary of the Dewey Decimal Classification, is beyond the requirements of library reference service. Three areas stand out with particular emphasis: the social sciences, useful arts, and history. Within these groups were concentrated approximately 72 per cent of the questions. The following fields were well represented: political science, economics, law, administration, associations, medicine, engineering, biography, and modern history.

Four other studies, all concentrated in the public library field, show a very close similarity, in the distribution of questions, to the findings of the present investigation. ${ }^{13-16}$

At this point it is interesting to note that the specific character of the various libraries receiving the questions was apparently not a factor in the distribution. When the classification is restricted to libraries roughly homogeneous in function the same emphases appear. Thus, of the questions recorded by the public libraries, 69 per cent fell in the social sciences, useful arts, and history; the same proportion of questions in the college and university libraries fell in

${ }^{13}$ Charters. W. W. "College Preparation for Reference Work." School and Society 27:150-52, 1928.

14 Rozendal, Hendrine. "Study of the Reference Service of the Davenport, Iowa, Public Library for the Period from I925-1935." Unpublished master's thesis. Library School, University of Illinois, 1936.

15 Conner, op. cit. "Books and Other Sources Used in Adult Reference Service in Branches of the Brookinn Public Library." Unpublished master's thesis, School of Library Service, Columbia University, I938. these fields; and of the questions asked in special libraries, 80 per cent were so classified.

The occupational classification of reference patrons used in this study was one employed by Haygood in his analysis of the use of the New York Public Library. ${ }^{17}$ Since some questions came from representatives of organizations, a category was added to provide for them. Out of 1026 questions asked, it was found that the concentration appeared among students (356) and professionals (210). The student group asked the largest numbers of questions in political science, economics, law, medicine, agriculture, literature, biography, and modern history. The fields in which professional workers asked the most questions are political science, administration, language, and engineering. Although the small number of questions asked by other occupational groups is scattered widely over the subject fields, we find that the questions of skilled laborers fell largely within the useful arts group, that most of the questions from shopkeepers and salesmen were about topics classified as social sciences and the useful arts, and that questions from clerical workers fell chiefly in the social science group.

In a further attempt to define the characteristics of reference work, a new classification was devised, one based on the historical period in which the questions fell. For this purpose the following divisions were set up:

I Questions pertaining to events, techniques, aesthetic or technical creations, or persons, in the current year

II Questions pertaining to the twentieth century

III Questions pertaining to modern times (i.e., from the Reformation to the end of the

17 Haygood, William Converse, ed. Who Uses the Public Library: $A$ Survey of the Patrons of the Circulation and Reference Departments of the New York Public Library. (Studies in Library Science.) Chi$P$ ublic Library. (Studies in Library Science.)
cago, University of Chicago Press, 1938, p. 72. 
Occurrence of Reference Questions, as Revealed by Several Enquiries

\begin{tabular}{lccccr} 
D.C. Classes & Present Study & Charters & Rozendal & Conner & Chait \\
\hline $000 \ldots \ldots$ & $5.5 \%$ & $2.5 \%$ & $4.2 \%$ & $2.0 \%$ & $3.0 \%$ \\
$100 \ldots \ldots$ & 1.5 & 1.5 & 0.9 & 1.0 & 0.5 \\
$200 \ldots \ldots$ & 1.8 & 2.2 & 1.8 & 2.8 & 1.7 \\
$300 \ldots \ldots$ & 37.3 & 22.7 & 21.7 & 21.2 & 29.5 \\
$400 \ldots \ldots$ & 3.1 & 2.4 & 4.9 & 2.0 & 1.2 \\
$500-600 \ldots$ & 22.9 & 18.0 & 12.3 & 33.0 & 22.0 \\
$700 \ldots \ldots$ & 6.7 & 11.0 & 8.1 & 6.8 & 6.2 \\
$800 \ldots \ldots$ & 4.7 & 12.5 & 11.4 & 11.0 & 4.3 \\
$900 \ldots \ldots$ & 16.5 & 24.2 & 27.2 & 17.0 & 31.6 \\
& & & $7.8^{*}$ & &
\end{tabular}

* Local and library questions

nineteenth century)

IV Questions pertaining to the middle ages

$\mathrm{V}$ Questions pertaining to ancient times

VI Questions pertaining to no one time period; those which cover several periods; those which are not readily classifiable by a time scheme

VII Questions pertaining to future events.

It should be noted that the time periods are by no means equal in length. Whereas types I and II combined cover less than half a century, types III, IV, and V each cover several hundred years. When the questions are classified by this method, it becomes clear that most patrons ask about events or creations relevant to the present century. Seventy-two per cent of the questions were classified as types I and II. It is evident, also, that in the subject fields where the largest numbers of questions are asked, the "time" emphasis is found in the most recent categories. Thus, 343 of the 383 questions in the social sciences were classified as types $I$ and II, and I 45 of the I 79 useful arts questions were classified likewise. In the third field, history, there is somewhat less emphasis on events, creations, or personalities of the present century, although 93 of the 172 questions fall within the two most recent categories.

Certain areas of inquiry do not fit into a time classification at all. For such ques- tions, type VI was established. Thus, 20 of the 3 I questions on language did not fit into any one period. Nearly half of the questions on pure science were not classifiable by time.

Among the existing classifications of reference questions the one devised by Carter Alexander ${ }^{18}$ permits the most accurate description of the nature of the question, apart from the subject matter of the question itself. He lists the following types of reference questions:

I. Fact type
(a) Meaning type
(b) Numerical or statistical type
(c) Historical type
(d) Exact wording type
(e) Proper name type

2. How to do type

3. Trends type

4. Supporting evidence type

5. "All about" type

6. Evaluation of reference type

7. Duplication of previous work type.

When the attempt was made to classify the questions according to this scheme it was found that many questions did not fit any of the categories suggested by Alexander. In fact, only little more than half could be classified by this scheme. It was necessary, therefore, to extend the classification to

is Alexander, op. cit. 
accommodate the remaining questions. The following additional categories were adopted :

I.

(f) Addresses of individuals and societies

(g) Facts about books and publishing

(h) Reviews of books, plays, and motion pictures

(j) Facts about specific individuals (as opposed to type I (e) which was used for such questions as, "What is the name of the ruler of Iraq?"

This new type covers biographical facts about persons whose names are known to the reader.)

(k) Requests for illustrations

(l) Geographical facts

8. "General information on subject" type. This category was adopted in place of Alexander's "all about" type, which was designed to cover general information questions which are phrased in a particular way

9. "Review" type (for example, material for a review of high school algebra)

Io. Historical discussions (opposed to I (c) historical facts)

II. Requests for bibliographies

12. Requests for the translation of passages

13. Requests for the preparation of reports and questionnaires.

The four types in which the overwhelming proportion of questions fall are: I. Fact type, 55 per cent; 2. How to do type, Io per cent; 4. Supporting evidence type, 8 per cent; and 8. General information of subject type, 20 per cent. Together they account for 93 per cent of the questions. Illustrations of the major types follow:

I. Fact type

What cities have daylight saving time? Who invented the quadratic equation?

2. How to do type

How to convert a furnace into an oil burner

How to remove stains from clothing

4. Supporting evidence type

Do colonies pay? (i.e., are they profitable to the mother country?)
Arguments for and against the consolidation of railroads

8. General information on subject type

Information on cosmetics

Material on structural engineering

The sources used in answering these types of questions are discussed below.

All reference librarians are aware of the great difficulty patrons have in making their exact and specific wants known. This difficulty is not limited to the uneducated but extends to the more sophisticated members of the population. An attempt was made in this section to determine the extent of the tendency and to point out specific types of confusion between what was requested and what was wanted.

The number of public library readers who failed to ask for exactly what they wanted is exceedingly small. Only 5 readers out of 467 were guilty of this. In the academic libraries 45 readers, or nearly 2 I per cent of the total, did not ask in specific terms for the material which they needed. Several persons asked for specific titles or kinds of publications which they mistakenly thought would contain the answer to the question. For example, a student asked for "reports of the Bureau of Standards." He wanted material on the quantitative analysis of part-wool samples; this material was supplied by means of the Chemical Abstracts. The error made most frequently by students, however, was to request material on a large subject when some particular aspect was desired. Nearly I I per cent of readers in special libraries had similar difficulty in expressing their exact needs.

Only a small proportion of the questions asked in the three types of libraries were unanswered. About 4 per cent of the public library questions, 9 per cent of the college and university questions, and 12 per cent of the special library questions were unanswered or only partially answered. 
The reasons given most frequently by reference librarians are:

The material was not in the library

The material desired was too recent to be in print

The question was outside the scope of the library.

\section{Sources of Reference Information}

Since the answers to many questions can be found in several places, from a functional point of view there is no source which can be considered better than any other except in terms of the needs of specific individuals. Furthermore, when we examine the books used by reference librarians in answering a group of questions, we must realize that the factors of accessibility and personal preference play a part in their selection. The only assumption upon which a description of books used in reference work can be based is that the books represent types of material generally found to be useful.

When the sources used to answer the present sample of questions were classified by type, it became evident that reference books represented about half of the sources used in answering factual questions. Five hundred and thirty-nine sources were used to answer 408 such questions; 298 , or 55 per cent, were classified as reference materials. The dependence upon reference books varied in the groups of factual questions. Reference books represented onethird of the sources used for statistical questions; in the groups of historical questions, exact wording questions, and proper name questions, reference books represented half, or slightly more than half, of the sources used. Reference books were used most heavily to answer questions relating to books and publishing and to furnish biographical facts. In the latter group, reference books constituted three-quarters of the source material. Non-reference, or "circulating," books accounted for 18 per cent of the source material. Periodicals and documents each accounted for one-tenth of the material, while newspapers represented 3 per cent and pamphlets 4 per cent of the total sources used.

Half of the group of "how to do" questions were answered by one source of information. Fifty-three per cent of the sources used to answer these questions were non-reference materials. However, Post's Etiquette and the World Almanac were frequently used, and the Readers' Guide to Periodical Literature was the title most often referred to.

Only 2 I of the 74 "supporting evidence" questions were answered through the use of one source of information. Two hundred and five sources were used in answering these questions. Of these, $3 \mathrm{I}$ were classified as reference books, 83 as nonreference books, 64 as periodicals, if as documents, 3 as newspapers, and Io as pamphlets. Non-reference books and periodicals combined accounted for nearly three-fourths of the source materials. The average question required the use of three sources of information.

Thirty-eight per cent of the "general information on subject" questions were answered in one source of information. Classification of source material by form showed 26 per cent to be reference books, 43 per cent non-reference books, 22 per cent periodicals, 7 per cent documents, and 2 per cent pamphlets. Thus, reference books account for about one-fourth of the sources used and non-reference books and periodicals for about two-thirds.

\section{Conclusion}

Classification of questions by subject is the method employed in five studies, including the present one. In all of these studies, the Dewey Decimal Classification has been used for a purpose for which it was not originally intended. In classifying 
the questions upon which this study is based, it was apparent that certain decisions or compromises, not entirely objective in nature, had to be made; for example, does a question about the political ideas of John Locke classify as political theory or modern philosophy? In a college library, does a question about urban recreational facilities asked by a student of sociology classify with recreation, a division of the fine arts, or with some phase of sociology? Such decisions may alter the results of subject classification to a marked degree. If the decimal system is used for this purpose, extreme care and objectivity is necessary. Of course, the patron's point of view will in some cases determine the best classification for a question. No one is in a better position to classify questions objectively than the reference librarian who answers them.

A problem for investigation in the field of reference work is implied in the foregoing discussion; that is, the development of a new subject classification scheme for reference questions, or, possibly, an adaptation of one of the systems of book classification now in use. A comparison of, for example, the decimal, Library of Congress, and Bliss classifications in relation to reference questions might provide guidance.

We have seen that five classifications of reference questions by subject reveal that the fields of social science, useful arts, and history, contain the largest numbers of questions asked. One cannot assume that these. areas will always be quantitatively the most important. Assuming that changes in subject emphasis will occur in time, the method of subject classification will continue to be useful as a means of showing these changes. Data showing the trends in reference work over a period of years will be useful in planning the development of the book stock and in specifying the qualifications needed by the reference personnel. Studies of the trends in reference work will aid library schools in keeping reference instruction realistic and up to date.

In this study an attempt was made to learn what occupational groups made use of the library reference service. It was pointed out that the character of the occupational groups in college and university libraries and special libraries may be determined by the nature of the institution. It was, therefore, not surprising to find that students ask most of the questions in the academic libraries and that professional persons are the most frequent users of the special library reference service. In the public library the reference service is established to meet the needs of persons from all occupational groups, but in the present study it was found that the persons who asked questions most frequently were those most accustomed to the use of books, the professionals and students.

The classification of reference questions by "time" periods showed so clearly the emphasis on recent events that a refinement of the technique might well be applied to other samples of questions. It seems particularly desirable to know the relationship of events and reference questions because of the implications for staff and for necessary resources. What is the length of time which elapses between a "current event" and a reference question about the event?

We have conventionally tended to identify reference work with reference books. As has been shown, a good part of reference work is definitely related to reference books, but other materials are used as well. Therefore, we might well devote increasing attention to the specific nature of the materials which are useful in reference work. 